\title{
NEW FLUORESCENT CROSSLINKED AROMATIC POLYAMIDES CONTAINING THIOPHENEAND FURANE IN THEIR BACKBONE
}

\author{
C. O. SÁNCHEZ ${ }^{\prime *}$, P. SOBARZO', N. GATICA², D. MAC-LEOD-CAREY3 \\ ${ }^{1}$ Instituto de Ciencias Químicas, Facultad de Ciencias, Universidad Austral de Chile, \\ Avda. Las Encinas 220, Campus Isla teja, Valdivia, Chile. \\ ${ }^{2}$ Departamento de Polímeros, Facultad de Ciencias, Universidad de Concepción, Chile, Avda. Edmundo Larenas 129, Concepción, Chile. \\ ${ }^{3}$ Universidad Autónoma de Chile, Avda. Pedro de Valdivia 641, Providencia, Santiago, Chile.
}

\begin{abstract}
New fluorescent crosslinked aromatic polyamides containing phenylen, thiophene and furane groups in the main chain were synthesized by self-condensation from 3-(5-aminothiophen-2-yl)propenoic acid, 3-(5-aminofuran-2-yl)propenoic acid and 3-(4-((5-aminothiophen-2-yl)methyleneamino)phenyl)propenoic acid using the phosphorylation method and triphenylphosphite as initiator. The amino compounds were obtained from 3-(5-nitrothiophen-2-yl)propenoic acid, 3-(5-nitrofuran-2-yl)propenoic acid and 3-(4-((5-nitrothiophen-2-yl)methyleneamino)phenyl)propenoic by selective reduction of each nitro group and was confirmed by ${ }^{1} \mathrm{H}-\mathrm{NMR}$ and FT-IR spectroscopy. Crosslinking of polyamides ocurr by mechanism between vinyl side groups reacts with the vinyl carbon of another chain, giving rise to interchain linear crosslinking. Depending on the structure the polymers have higher degree of crosslinking. Some vinyl groups react by thermal treatmentat $200^{\circ} \mathrm{C}$. Partially crosslinked polyamides with high emission fluorescence were obtained. Consequently amide bond formation, crosslinking and conjugation are the main factors that influence the fluorescence process. While polymers have several factors that affect the fluorescence, we believe that the most significant is the crosslinking of vinyl bonds. Subsequent thermal treatment of polyamides provoked crosslinking increase and fluorescence loss. The effect of the chemical structure was correlated with the thermal decomposition. Polyamides were characterized by UV-visible, FT-IR and ${ }^{1} \mathrm{H}-\mathrm{NMR}$ spectroscopy, inherent viscosity and thermogravimetric analysis (TGA). The synthesized polyamides exhibited potential for heat sensitive devices application since the fluorescence can be activated or quenched according to a heating process.
\end{abstract}

\section{INTRODUCTION}

Aromatic polyamides have high thermal stability and good mechanical properties Usually they are intractable, sparingly soluble materials with high softening temperature and therefore, poor proccesability ${ }^{1-3}$. Various studies have been conducted by means of synthetic modifications using, for example, flexible linkages[4-6], pendent, bulky, alkyl side groups, luminous aliphatic, cyclic and vinyl bonds ${ }^{7-11}$ in the polymer backbone. Polyamides with vinyl groups in their backbones after to be pyrolysed have electrical conductivity 12. Several soluble polyamides with pendent cyano groups have been reported 13,14 . The cyano groups enable the synthesis of heat-resistant cross-linkable polymers with high thermal stability (up to $370{ }^{\circ} \mathrm{C}$ ). Others polymers that can be crosslinked are those containing vinyl bonds in the main chain ${ }^{11,15-17}$ Polymers containing crosslinkable functional groups are interesting since they have practical applications in optoelectronics ${ }^{18}$. On the other hand, research on photonic devices using organic materials has received much attention. Very often polymers having phenylene-vinylene, thiophene and furane units in their backbone are utilized in such devices ${ }^{19-22}$.

On the other hand, researchers have been interested in the synthesis and characterization of fluorescent polymers, e.g. poly(thiophene) substituted with alkylsulfanyl carboxylic acid group exhibit a high fluorescence quantum yield ${ }^{23-25}$. A high fluorescence yield is a prerequisite for an electro-luminescent polymeric material, particularly application of conjugated polymers in organic light emitting devices (OLED) utilizing their fluorescence properties ${ }^{26,27}$, moreover, fluorescent polymeric films may be used as sensors, using an analyte quencher ${ }^{28,29}$, enantiomers ${ }^{30}$ or metallic ions ${ }^{31}$. A reversible $\mathrm{pH}$ sensor for aqueous media based on the fluorescence properties of a poly(thiophene)-gold nanoparticles composite have been reported ${ }^{32}$.

The objective of the present work is the synthesis and characterization of new fluorescent crosslinked aromatic polyamides containing thiophene and furane in the main chain. A subsequent thermal treatment of polyamides enabled additional crosslinking. Properties such as thermal stability and fluorescence emission were studied. Synthesis and spectroscopic characterization of monomers and new aromatic polyamides are reported.

\section{EXPERIMENTAL}

\section{Measurements}

I.R. spectra were recorded on a JASCO FT-IR 4200 spectrometer. NMR spectra were registered using TMS as internal reference on a $400 \mathrm{MHz}$
Bruker spectrometer. UV-Vis spectra were taken on a Perkin-Elmer Lambda 35UV/VIS Spectrometer. Spectra were obtained from a $0.38 \mathrm{gL}^{-1}$ polymers solution in DMSO. Fluorescence spectra were recorded on a Jasco FP-6200 Spectrofluorometer. Elemental analysis was accomplished on a EA-1108 Fisons Elemental Analyzer. Polymers thermal analysis was carried out at a heating rate of $20^{\circ} \mathrm{C} \mathrm{min}-1$ under nitrogen using a TGA Q 50 V20.5 thermal analyzer. Melting points were determined with a Kofler melting point apparatus SMP10. All the measurements were performed under the same conditions. Crosslinking was accomplished placing polyamides into a glass tube and heating by 20-30 min at $200{ }^{\circ} \mathrm{C}$ in an oven provided with a digital thermometer.

Reagents and monomers

3-(p-aminophenyl)propenoic acid hydrochloride, DMSO, triphenylphosphite, LiCl, 5-nitrofuran-2-carboxaldehyde, 5-nitrothiophene2 -carboxaldehyde, malonic acid, pyridine, $\mathrm{NH} \mathrm{Cl}, \mathrm{Zn}$ powder, $\mathrm{Sn}$ grain were purchased from Sigma-Aldrich. 3-(5-aminothiophen-2-yl)propenoic acid, 3-(5-aminofuran-2-yl)propenoic and 3-(4-(((5-aminothiophen-2-yl)methylene) amino)phenyl)propenoic acid were synthesized by selective reduction from the respective nitro-aryl-carboxylic acid compound. 3-(5-nitrofuran2-yl)propenoic and 3-(5-nitrothiophen-2-yl)propenoic acid were prepared by condensation between malonic acid and 5-nitrofuraldehyde and 5-nitrothiophene-2-carboxaldehyde respectively in the presence of pyridine. 3-(4-((5-nitrothiophen-2-yl)methyleneamino)phenyl) propenoic acid was synthesized by condensation between 3-(p-aminophenyl)propenoic acid and 5-nitrothiophene-2-carboxaldehyde.

\section{Synthesis}

3-(5-nitrothiophen-2-yl)propenoic acid: A $20 \mathrm{~mL}$ round-bottom flask, equipped with a reflux condenser, was charged with $0.82 \mathrm{~g}(7.9 \mathrm{mmole})$ malonic acid, $1.00 \mathrm{~g}(6.4 \mathrm{mmole}) 5$-nitrothiophene-2-carboxaldehyde and 0.62 $\mathrm{g}(7.8 \mathrm{mmole})$ pyridine. The mixture was heated in an oil bath and once a solid is formed $0.62 \mathrm{~g}$ pyridine was added. The reaction mixture was gradually heated to $150{ }^{\circ} \mathrm{C}$, maintained for five minutes at that temperature and then cooled to room temperature. 20 drops pyridine and $10 \mathrm{~mL}$ boiling water were poured into the mixture followed by decantation and filtration of the warm supernatant. The process was repeated several times until complete solid solubilization. The filtered were cooled to room temperature and next acidified to $\mathrm{pH} 0-2$ by the addition of $\mathrm{HCl}(37 \%)$. After standing for $1 \mathrm{~h}$ the solid were separated by filtration. The solid products were jointed and dried at $60{ }^{\circ} \mathrm{C}$ in an oven. $0.84 \mathrm{~g}$ of a yellow-brown product was obtained, $66.3 \%$ yield, $\mathrm{mp}=256^{\circ}$ $\mathrm{C}$ (decomposed). FT-IR: $\mathrm{OH}$, at $3200-2500 \mathrm{~cm}^{-1}, \mathrm{C}=\mathrm{O}$, at $1688 \mathrm{~cm}^{-1}, \mathrm{C}=\mathrm{C}$, at 
$1529 \mathrm{~cm}^{-1}, \mathrm{NO}_{2-}^{-}$, at $1489 \mathrm{~cm}^{-1}$ and at $1430 \mathrm{~cm}^{-1}, \mathrm{C}-\mathrm{O}$ at $1206 \mathrm{~cm}^{-1}$, vinyl bond at $1623 \mathrm{~cm}^{-1}$. ${ }^{2} \mathrm{H}-\mathrm{NMR}$ (DMSO-d6): aromatic $\mathrm{CH}$ at $8.12 \mathrm{ppm}(1 \mathrm{H}, \mathrm{d}) ; \mathrm{CH}$ at $7.63 \mathrm{ppm}(1 \mathrm{H}, \mathrm{d})$; vinyl $\mathrm{CH}$ at $7.75 \mathrm{ppm}(1 \mathrm{H}, \mathrm{d})$, vinyl $\mathrm{CH}$ at $6.60 \mathrm{ppm}(1 \mathrm{H}, \mathrm{d})$; -OH at 12.70 ppm. Elemental analysis, Calcd.: C 42.2, H 2.5, N 7.0, S 16.10. Found: C 41.0, H 1.6, N 6.0, S 12.13.

3-(5-aminothiophen-2-yl)propenoic acid, (ATPA): In a $50 \mathrm{~mL}$ roundbottom flask, equipped with a reflux condenser $0.83 \mathrm{~g}$ (4.16 mmole) 3-(5-nitrothiophen-2-yl)propenoic acid, $27 \mathrm{~mL}$ acetic acid, $1.1 \mathrm{~mL}$ water, six drops $37 \% \mathrm{HCl}$ were placed and the mixture was heated to $95-100{ }^{\circ} \mathrm{C}$. Once dissolved $(10 \mathrm{~min}), 0.60 \mathrm{~g}$ tin was added and after $20 \mathrm{~min} 0.28 \mathrm{~g}$ tin and 5 drops $\mathrm{HCl}(37 \%)$ were added. The reaction mixture was refluxed for $2 \mathrm{~h}$ after which the hot mixture was filtered, concentrated to half its volume followed by volume duplication with water. The mixture was left standing for $48 \mathrm{~h}$ and then vacuum-filtered, washed with a small amount of water and finally dried at 60 ${ }^{\circ} \mathrm{C}$. $0.30 \mathrm{~g}$ of product was obtained, $42.5 \%$ yield. $\mathrm{mp}>$ at $300^{\circ} \mathrm{C}$. FT-IR: $\mathrm{NH}$ $+\mathrm{OH}$, at 3700-3000 $\mathrm{cm}^{-1}, \mathrm{C}=\mathrm{O}$, at $1688 \mathrm{~cm}^{-1}, \mathrm{C}-\mathrm{O}$ at $1206 \mathrm{~cm}^{-1}$, vinyl bond at $1618 \mathrm{~cm}^{-1} .{ }^{1} \mathrm{H}-\mathrm{NMR}$ (DMSO-d6): aromatic $\mathrm{CH}$ at $8.10 \mathrm{ppm}(1 \mathrm{H}, \mathrm{d}) ; \mathrm{CH}$ at 7.60 ppm $(1 \mathrm{H}, \mathrm{d})$; vinyl $\mathrm{CH}$ at $7.75 \mathrm{ppm}(1 \mathrm{H}, \mathrm{d})$, vinyl $\mathrm{CH}$ at $6.58 \mathrm{ppm}(1 \mathrm{H}, \mathrm{d}) ;-\mathrm{OH}$ at $12.6 \mathrm{ppm}, \mathrm{NH}_{2}$ at $2.50 \mathrm{ppm}$.

3-(5-nitrofuran-2-yl) propenoic acid: In a $50 \mathrm{~mL}$ round-bottom flask, equipped with a reflux condenser $3.0 \mathrm{~g}$ (17 mmole) 5-nitrofuraldehyde, 2.46 $\mathrm{g}(24 \mathrm{mmole})$ malonic acid and $1.86 \mathrm{~g} \mathrm{(24} \mathrm{mmole)} \mathrm{pyridine} \mathrm{were} \mathrm{placed.} \mathrm{The}$ mixture was heated to $150^{\circ} \mathrm{C}$, cooled to room temperature, next, the solid was extracted two times using $20 \mathrm{~mL}$ ethanol to boiling and then, again extracted the solid with ethanol to boiling that contain 20 drops pyridine, the extraction process of the solid using a mix ethanol-pyridine was repeated five times, then all the extracts were boiled and filtered. The filtrates were gathered and concentrated to half its volume by solvent evaporation. The mixture volume was duplicated by adding water, and finally acidified with $\mathrm{HCl}(37 \%)$ to $\mathrm{pH}$ $0-2$ under stirring. The obtained mixture was left standing for $2 \mathrm{~h}$ and then filtered. The solid product was dried at $60{ }^{\circ} \mathrm{C}$ in an oven. $1.20 \mathrm{~g}$ of product was obtained $(30.0 \%$ yield $), \mathrm{mp}=158-160^{\circ} \mathrm{C}$ (decomposed). FT-IR: OH, at 2906 $\mathrm{cm}^{-1}$ (broad), $\mathrm{C}=\mathrm{O}$, at $1678 \mathrm{~cm}^{-1}, \mathrm{C}=\mathrm{C}$, at $1573 \mathrm{~cm}^{-1}, \mathrm{C}-\mathrm{O}$ at $1201 \mathrm{~cm}^{-1}$, vinyl bond at $1623 \mathrm{~cm}^{-1} .{ }^{1} \mathrm{H}-\mathrm{NMR}$ (DMSO-d6): aromatic $\mathrm{CH}$ at $7.76 \mathrm{ppm}(1 \mathrm{H}, \mathrm{d})$; $\mathrm{CH}$ at $7.28 \mathrm{ppm}(1 \mathrm{H}, \mathrm{d})$; vinyl $\mathrm{CH}$ at $7.46 \mathrm{ppm}(1 \mathrm{H}, \mathrm{d})$, vinyl $\mathrm{CH}$ at $6.51 \mathrm{ppm}$ $(1 \mathrm{H}, \mathrm{d}) ;-\mathrm{OH}$ at $12.88 \mathrm{ppm}(1 \mathrm{H}, \mathrm{s})$. Elemental analysis, Calcd.: C 45.9, H 2.8, N 7.6, O 43.7. Found: C 44.8, H 2.4, N 6.6, O 46.2.

3-(5-aminofuran-2-yl)propenoic acid, (AFPA):A $20 \mathrm{~mL}$ round-bottom flask, equipped with a reflux condenser it was charged with $0.45 \mathrm{~g}(2.5 \mathrm{mmole})$ 3-(5-nitrofuran-2-yl)propenoic acid, $8 \mathrm{~mL}$ acetic acid, $0.6 \mathrm{~mL}$ water and 3 drops $37 \% \mathrm{HCl}$ and the mixture was heated and once solubilized, $0.30 \mathrm{~g}$ tin was added and refluxed under stirring during $100 \mathrm{~min}$. The hot mixture was filtered and the filtrate was concentrated to half its volume by evaporation, cooled to room temperature, its volume duplicated with water, left standing, and finally filtrated and dried at $60{ }^{\circ} \mathrm{C}$ in an oven. $0.14 \mathrm{~g}$ was obtained. (33.2 \% yield), $\mathrm{mp}$ $>300^{\circ} \mathrm{C}$. FT-IR: $\mathrm{OH}$, at $3423 \mathrm{~cm}^{-1}, \mathrm{C}=\mathrm{O}$, at $1718 \mathrm{~cm}^{-1}, \mathrm{C}=\mathrm{C}$, at $1655 \mathrm{~cm}^{-1}, \mathrm{C}-\mathrm{O}$ at $1231 \mathrm{~cm}^{-1}$, vinyl bond at $1589 \mathrm{~cm}^{-1} .{ }^{1} \mathrm{H}-\mathrm{NMR}$ (DMSO): aromatic $\mathrm{CH}$ at 7.0 ppm $(1 \mathrm{H}, \mathrm{d}) ; \mathrm{CH}$ at $6.9 \mathrm{ppm}(1 \mathrm{H}, \mathrm{d})$; vinyl $\mathrm{CH}$ at $7.2 \mathrm{ppm}(1 \mathrm{H}, \mathrm{d})$, vinyl $\mathrm{CH}$ at $6.5 \mathrm{ppm}(1 \mathrm{H}, \mathrm{d}) ; \mathrm{NH}_{2}$ at $3.6 \mathrm{ppm}$.

3-(4-(((5-nitrothiophen-2-yl)methylene)amino)phenyl)propenoic acid: In a $100 \mathrm{~mL}$ round-bottomed flask, equipped with a reflux condenser, were

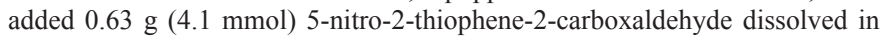
$20 \mathrm{~mL}$ of heated ethanol, $0.80 \mathrm{~g}(4.0 \mathrm{mmole}) 3$-(p-aminophenyl)propenoic acid hydrochloride dissolved in $40 \mathrm{~mL}$ hot ethanol, the mixture was heated during 1 $\mathrm{h}$ under stirring, then, it was immediately vacuum filtered. The solid was then washed with ethanol and dried at $60^{\circ} \mathrm{C} .0 .17 \mathrm{~g}$ product was obtained (yield $14.1 \%$ ). $\mathrm{mp}=276^{\circ} \mathrm{C}$ (decomposed). FT-IR: $\mathrm{OH}$, at $2816 \mathrm{~cm}^{-1}$ (broad), $\mathrm{C}=\mathrm{O}$, at $1678 \mathrm{~cm}^{-1}, \mathrm{NO}_{2}^{-}$, at $1489 \mathrm{~cm}^{-1}$ and $1420 \mathrm{~cm}^{-1}, \mathrm{C}-\mathrm{O}$ at $1211 \mathrm{~cm}^{-1}$, vinyl bond at $1618 \mathrm{~cm}^{-1}$. ' $\mathrm{H}-\mathrm{NMR}$ (DMSO-d6): $\mathrm{CH}$ thiophene ring at $8.20 \mathrm{ppm}(1 \mathrm{H}, \mathrm{d}) ; \mathrm{CH}$ thiophene ring at $7.75 \mathrm{ppm}(1 \mathrm{H}, \mathrm{d}) ; \mathrm{CH}=\mathrm{N}$ at $8.95 \mathrm{ppm}(1 \mathrm{H} ; \mathrm{s}) ; \mathrm{CH}$ phenylene at $7.78 \mathrm{ppm}(2 \mathrm{H}, \mathrm{d}), \mathrm{CH}$ phenylene at $7.39 \mathrm{ppm}(2 \mathrm{H}, \mathrm{d})$, vinyl $\mathrm{CH}$ at $7.61 \mathrm{ppm}$ $(1 \mathrm{H}, \mathrm{d})$, vinyl $\mathrm{CH}$ at $6.56 \mathrm{ppm}(1 \mathrm{H}, \mathrm{d}) ;-\mathrm{OH}$ at $12.5 \mathrm{ppm}(1 \mathrm{H}, \mathrm{s})$.

3-(4-(((5-aminothiophen-2-yl)methylene)amino)phenyl)propenoic acid, (ATIPA):

$1.0 \mathrm{~g}$ nitro-compound ( $3.3 \mathrm{mmol}), 25 \mathrm{~mL}$ de methanol, $2.8 \mathrm{~mL}$ of water, $0.52 \mathrm{~g} \mathrm{NH} C \mathrm{Cl} 50 \mathrm{~mL}$ were placed in a round-bottom flask equipped with a reflux condenser. The stirred mixture was heated for $10 \mathrm{~min}$ after which 3.5 $\mathrm{g}$ of $\mathrm{Zn}$ powder was slowly added. The mixture was now heated during 105 min at $71{ }^{\circ} \mathrm{C}$, and the hot mixture vacuum filtered, concentrated to half its volume, cooled in a water bath for $15 \mathrm{~min}$ or until separation of a solid occurs. The mixture was filtered, washed with ebulled methanol and dried at $60{ }^{\circ} \mathrm{C}$ in an oven. $0.17 \mathrm{~g}$ amino compound was obtained $(18.9 \%$ yield $), \mathrm{mp}=255^{\circ} \mathrm{C}$ (decomposed). FT-IR: $\mathrm{OH}$, at $3219, \mathrm{~cm}^{-1}$ (broad), $\mathrm{C}=\mathrm{O}$, at $1633 \mathrm{~cm}^{-1}, \mathrm{C}-\mathrm{O}$ at
$1249 \mathrm{~cm}^{-1}$, vinyl bond at $1598 \mathrm{~cm}^{-1} .{ }^{1} \mathrm{H}-\mathrm{NMR}$ (DMSO-d6): $\mathrm{CH}$ phenylen at $5.48 \mathrm{ppm}(2 \mathrm{H}, \mathrm{d}) ; \mathrm{CH}$ phenylen at $6.53 \mathrm{ppm}(2 \mathrm{H}, \mathrm{d}) ; \mathrm{CH}$ vinyl at $6.14 \mathrm{ppm}, \mathrm{NH}_{2}$ at $3.64 \mathrm{ppm}, \mathrm{CH}=\mathrm{N}+\mathrm{CH}$ vinyl $+\mathrm{CH}$ thiophene at $7.23 \mathrm{ppm}(4 \mathrm{H}, \mathrm{m})$.

Synthesis of polymers

Polyamides were synthesized under the same experimental condition using the phosphorylation method. Triphenylphosphite was used as initiator and polymers can be produced with higher molecular weight $t^{33}$. 3-(5-aminothiophen-2-yl)propenoic acid polymerization was accomplished as follow: to a $20 \mathrm{~mL}$ round-bottom flask equipped with a reflux condenser 1.54 mmol monomer, $0.72 \mathrm{~mL}$ DMF, $0.72 \mathrm{~mL}$ pyridine, $0.44 \mathrm{~g}$ triphenylphosphite and catalytic amounts of $\mathrm{LiCl}$ were added. The mixture was heated to $110-120$ ${ }^{\circ} \mathrm{C}$ for $17 \mathrm{~h}$, concentrated to half its volume, cooled to room temperature, 10 $\mathrm{mL}$ water added and stirred. After being left standing for $10 \mathrm{~min}$, the solid was filtrated off and successively washed with a small amount of $3 \mathrm{M} \mathrm{HCl}$, water, and methanol. The polymer was dried at $60{ }^{\circ} \mathrm{C}$ in an oven, and $0.24 \mathrm{~g}$ was obtained.

3-(5-aminofuran-2-yl) propenoic acid polymerization was performed using $1.1 \mathrm{~mL}$ DMF, $1.1 \mathrm{~mL}$ pyridine, $0.44 \mathrm{~g}$ triphenylphosphite, and for 3-(4-((5-aminothiophen-2-yl) methyleneamino)phenyl) propenoic acid polymerization $12.9 \mathrm{~mL}$ DMF, $4.8 \mathrm{~mL}$ pyridine and $0.97 \mathrm{~g}$ initiator were utilized. 0.22 and $0.071 \mathrm{~g}$ of the respective polymer was obtained.

In the present work, polyamides obtained from 3-(5-aminothiophene-2yl)propenoic acid and 3-(5-aminofuran-2-yl)propenoic acid were called PTPA and PFPA respectively. Monomers of those polymers are designated ATPA and AFPA respectively. Polyamide synthesized from 3-(4-((5-aminothiophen-2yl)methyleneamino) phenyl)propenoic acid is called PTIPA and its respective monomer ATIPA.

\section{RESULTS AND DISCUSSION}

Figure 1 depicts monomers synthesis scheme. 3-(5-nitrothiophene-2yl)propenoic acid, 3-(5-nitrofuran-2-yl)propenoic acid, were obtained by condensation of malonic acid with 5-nitrothiophene-2-carboxaldehyde and 5 -nitrofuraldehyde in the presence of pyridine. Selective reduction of the nitro compounds in the presence of vinyl bonds was accomplished using a $\mathrm{Sn} / \mathrm{AcOH} / \mathrm{HCl}$ mixture. 3-(4-((5-nitrothiophen-2-yl)methyleneamino) phenyl) propenoic reduction was performed using a $\mathrm{Zn} / \mathrm{NH}_{4} \mathrm{Cl} / \mathrm{H}_{2} \mathrm{O}$ mixture. $\mathrm{Sn} / \mathrm{AcOH} / \mathrm{HCl}$ mixture hidrolyzes the imine group and was thus discarded. Selective reduction of each nitro group was confirmed by ${ }^{1} \mathrm{H}-\mathrm{NMR}$ and FTIR spectroscopy. ${ }^{1} \mathrm{H}-\mathrm{NMR}$ exhibited vinyl hydrogen signals with a coupling constant of $17 \mathrm{~Hz}^{34}$
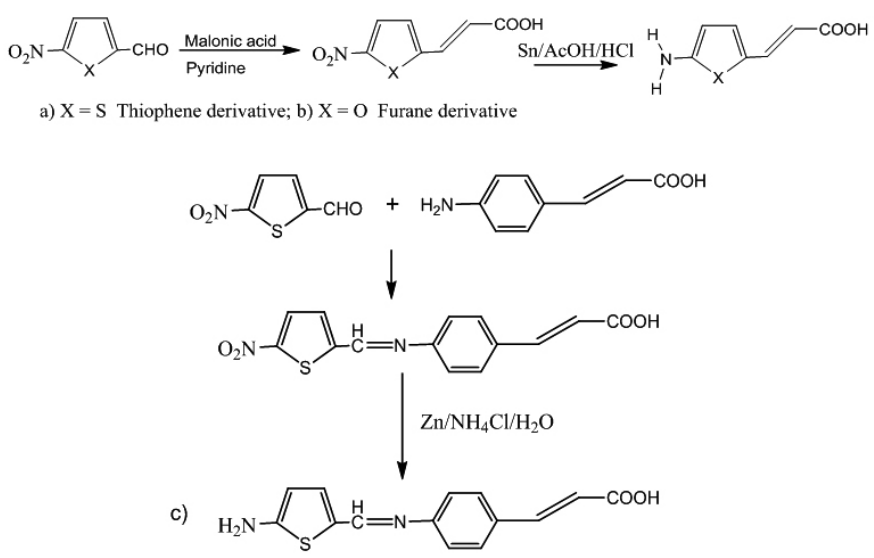

Fig. 1: Synthesis of a) ATPA, b) AFPA, c) ATIPA monomers

Polyamides FT-IR spectra are shown in Fig. 2. PTPA, PFPA and PTIPA show characteristic absorption bands at $3200 \mathrm{~cm}^{-1}(\mathrm{NH}+\mathrm{OH}) ; 1684,1713$, $1657 \mathrm{~cm}^{-1}(\mathrm{C}=\mathrm{O}) ; 1594,1593,1588 \mathrm{~cm}^{-1}$ (vinyl bond); 1483, 1490, $1487 \mathrm{~cm}^{-1}$ (aromatic $\mathrm{CH}=\mathrm{CH}$ ). The characteristic bands of carbonyl and $\mathrm{NH}$ group in all spectra confirm the presence of amide groups. 


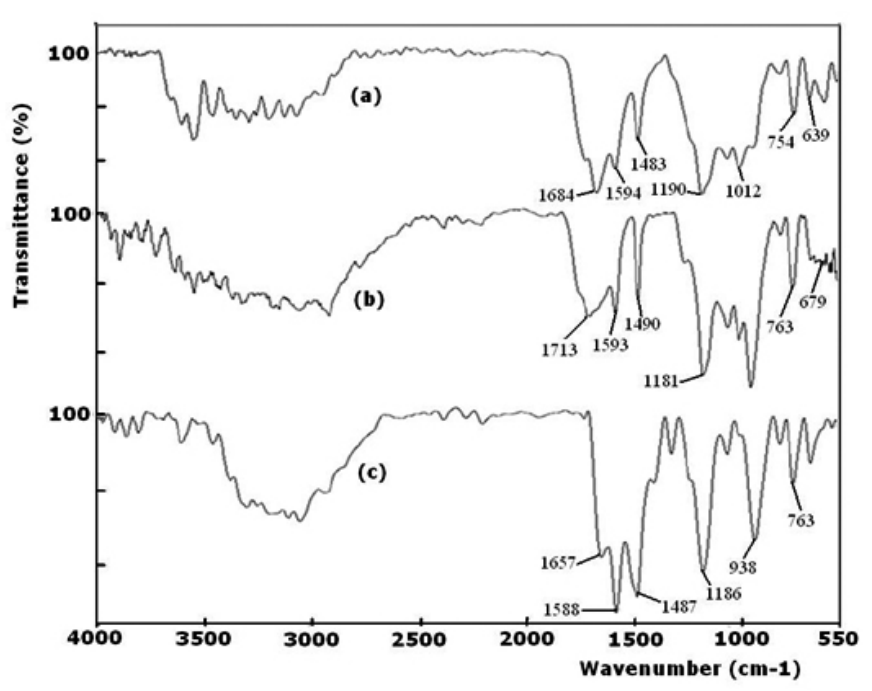

Fig. 2: Polyamides FT-IR spectra. a) PTPA, b) PFPA, c) PTIPA

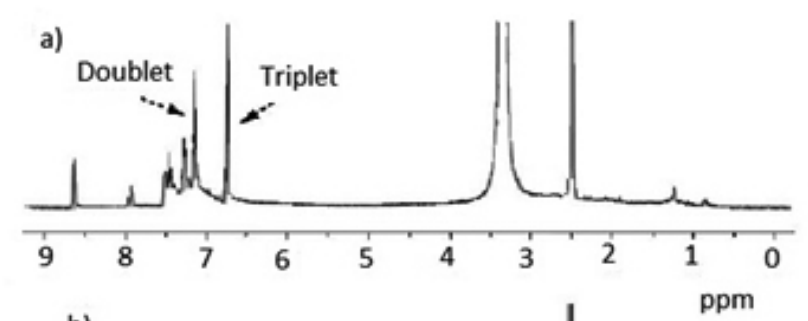

b)
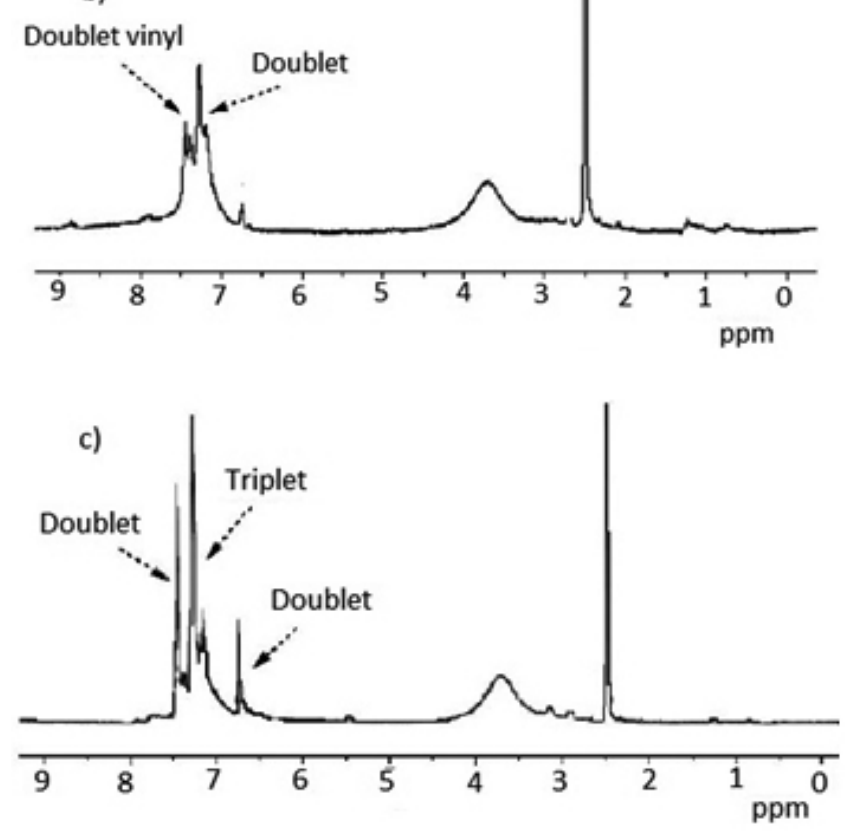

Fig. 3:Polyamides ${ }^{1} \mathrm{HNMR}$ spectra. a) PTPA, b) PFPA, c) PTIPA

${ }^{1} \mathrm{H}$-NMR spectra in Fig. 3 exhibit doublet and triplet signals in the aromatic region. The triplet signals in the aromatic region is a corroboration of polyamides crosslinking, therefore after polymerization two chemical processes are accomplished: i) formation of amide groups and, ii) crosslinking between the vinyl bonds of different chains. Using a standard structure (ethyl cinnamate), Sung et al. ${ }^{35}$, have reported two reaction mechanisms between vinyl side groups attached to polymer backbones that participate in the crosslinking. In the first mechanism one vinyl carbon reacts with the vinyl carbon of another chain, giving rise to interchain linear crosslinking. In the second mechanism, the two vinyl carbons react with two vinyl carbons of another chain affording an interchained cyclobutyl group. This mechanism is called addition $[2+2]$ and is based upon a pericyclic reaction. However, from an energetic view point, this reaction is rather hindered due to molecular orbital geometric constraint ${ }^{36,37}$. The absence of aliphatic signals and the presence of triplet signals in the aromatic indicating that the mechanism of crosslinking is predominant interchain linear (Fig. 4 a, b, c).
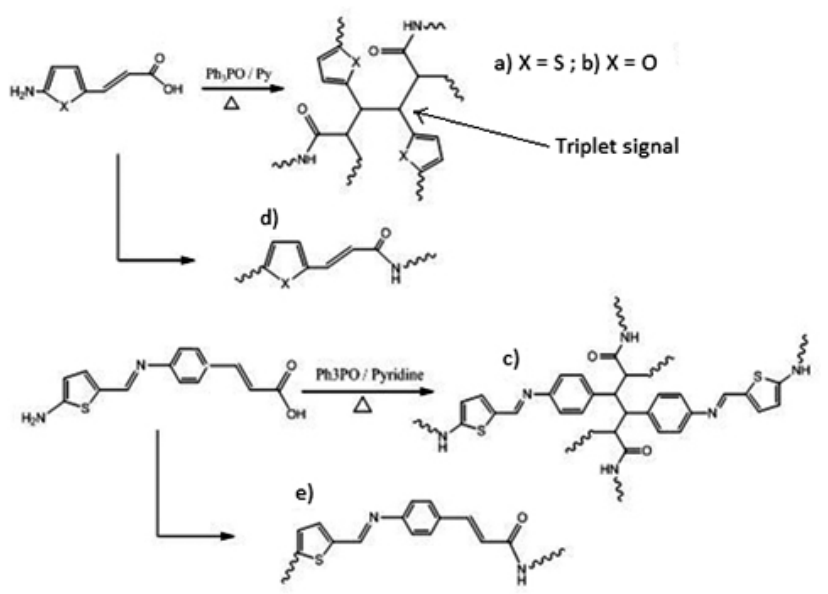

Fig. 4: Polyamides proposed structure, a) PTPA, b) PFPA, c) PTIPA

Not all the vinyl bonds are crosslinked by the polymerization, this is confirmed by optical absorption. Fig. 5 shows absorption spectra of polymers dissolved in DMSO. The absorption bands correspond to $\pi-\pi^{*}$ as well as n- $\pi^{*}$ transitions. PTPA and PFPA exhibited an absorption maximum at 270 and $260 \mathrm{~nm}$, apart from a broad plateau band at approximately $330 \mathrm{~nm}$. PTIPA has absorption maximum at $360 \mathrm{~nm}$ and shifts to higher wavelength than PTPA and PFPA due to the greater conjugation of its backbone. PFPA has a smaller PTPA conjugation and is due to the greater rupture in conjugation by formation of increased crosslinking.

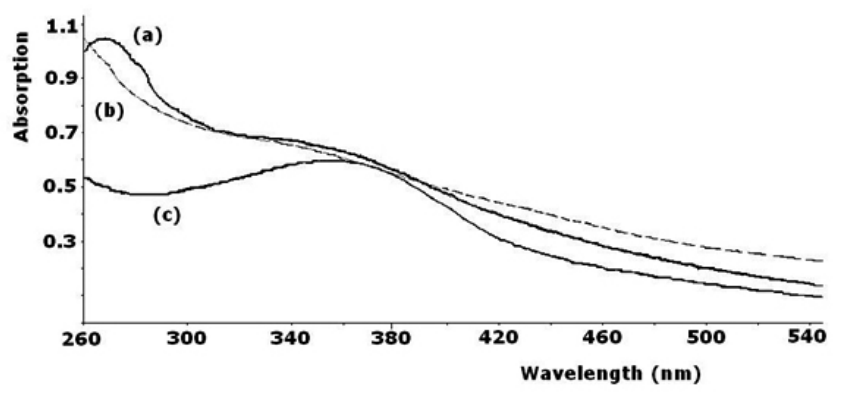

Fig. 5: Polyamides absorption spectra. a) PTPA, b) PFPA, c) PTIPA

Some vinyl groups react by thermal treatment. After thermal treatment, PTPA, PFPA,PTIPA bands are blue shifted 7, 8 and $11 \mathrm{~nm}$ respectively. This is confirmed measurement the intensity ratio between two absorption bands (Fig. 6), which were increased to $3.45,1.70$ and 1.23 for PTPA, PFPA and PTIPA respectively. The increased intensity ratio indicated the decreasing of conjugated system. These results indicated that the polymers reacted through some vinyl bonds that did not react during the polymerization process because a band shift is associated to conjugation loss, while the absorption ratio increase is related to vinyl group decrease. These results confirmed the presence of some vinyl groups in the polyamides, therefore non-crosslinked structural units do remain in the polyamides. The proposed structures are showed in Fig. $4 d$ and $4 \mathrm{e}$. 
(a)
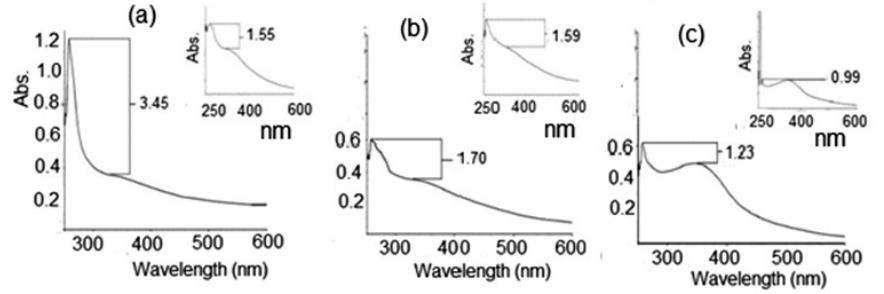

Fig. 6: Intensity ratio of two absorption bands. a) PTPA, b) PFPA, c) PTIPA. Insets, no thermal treatment

The Thermal treatment consisted in heating PFPA and PTIPA at $200{ }^{\circ} \mathrm{C}$ for $30 \mathrm{~min}$ and PTPA during $20 \mathrm{~min}$. The crosslinking temperature was chosen from thermograms (TGA) to obtain polymers without substantial mass loss or to avoid decomposition. The heating time was established by determining the time elapsed until the monitored FT-IR vinyl band intensity reached its lowest value. This heat-treatment afforded maximum crosslinking. Fluorescence results and thermal treatment of the polymers are displayed in Figs. 7 and 8. Emission at $660 \mathrm{~nm}$ correspond to second-order diffraction of the emission monochromator grating (exc. $330 \mathrm{~nm}$ ). PTPA and PFPA spectra are similar and exhibited high fluorescence emission. Quenching is produced in both polymers after thermal treatment, unlike PTIPA not show fluorescence emission (Fig. 7) and after thermal treatment is activated fluorescence reaching an intensity of 380 (Fig. 8).

While polymers have several factors that affect the fluorescence, we believe that the most significant is the crosslinking of vinyl bonds. In fact, we prepared poly(p-aminophenyl propenoic acid $)^{11}$ and this presents fluorescence activation by thermal treatment (Fig. 9), a similar result occurs in PTIPA.

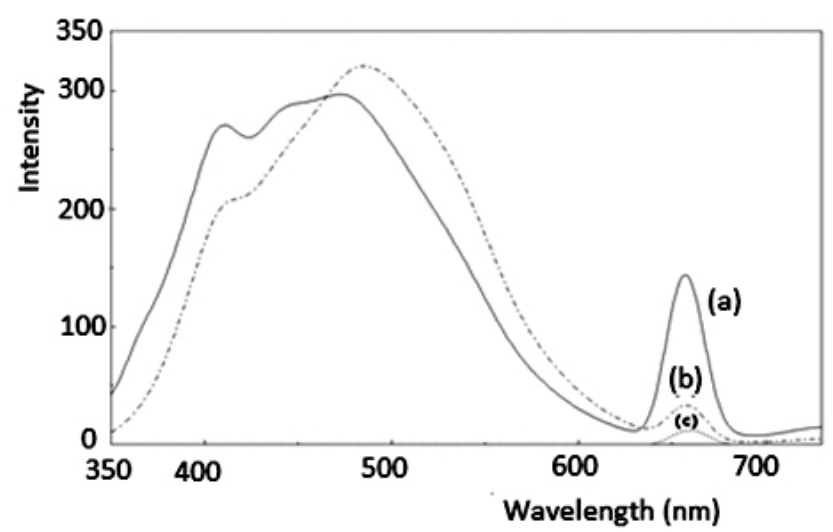

Fig. 7: Polymers fluorescence spectra. $\lambda$ exc at $330 \mathrm{~nm}$, a) PTPA, b) PFPA, C) PTIPA

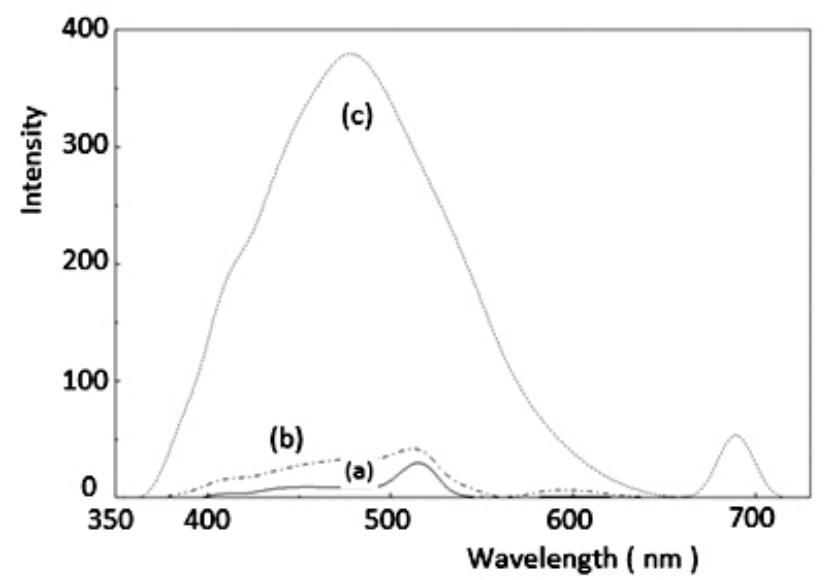

Fig. 8: Polyamides fluorescence spectra after thermal treatment. a) PTPA $\left.\left(\lambda_{\text {exc }}=258 \mathrm{~nm}\right), \mathrm{b}\right)$ PFPA $\left(\lambda_{\text {exc }}=258 \mathrm{~nm}\right)$, c) PTIPA $\left(\lambda_{\text {exc }}=347 \mathrm{~nm}\right)$.

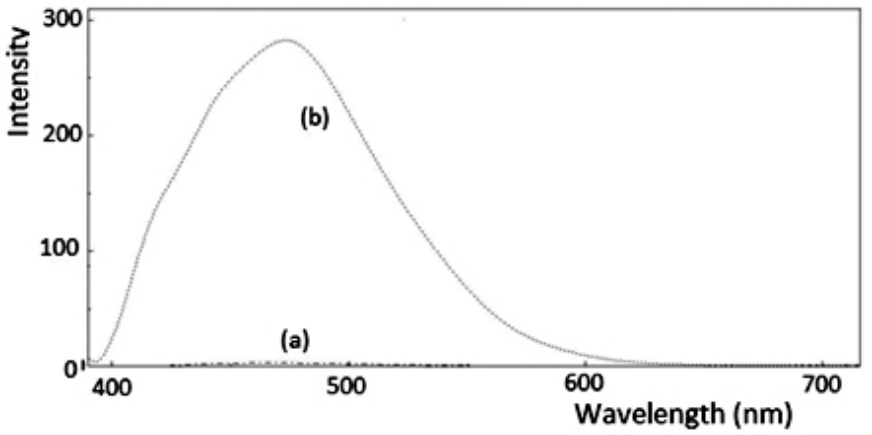

Fig. 9: Fluorescence spectra $(\lambda \operatorname{exc}=380 \mathrm{~nm})$ of a) poly(p-aminophenyl propenoic) and b) poly(p-aminophenyl propenoic) after thermal treatment.

PTPA, PFPA, PTIPA monomers are designated ATPA, AFPA, ATIPA respectively. Figure 10 shows the results of monomers fluorescence emission. The fluorescence of monomer and polymers are different. ATPA presented no fluorescence while AFPA displayed an intensity of 820 at $480 \mathrm{~nm}$. ATIPA exhibited maximum fluorescence emission at $425 \mathrm{~nm}$ with an intensity of 380 . Consequently amide bond formation, crosslinking and conjugation are the main factors that influence the fluorescence process.

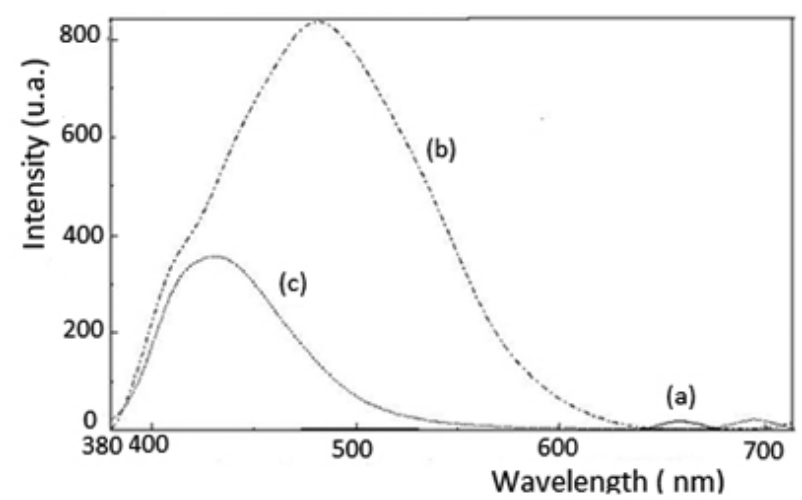

Fig.10: Monomers fluorescence spectra. a) ATPA $(\lambda \operatorname{exc}=330 \mathrm{~nm})$, (b) $\operatorname{AFPA}(\lambda \operatorname{exc}=367 \mathrm{~nm})$, C) ATIPA $(\lambda \operatorname{exc}=348 \mathrm{~nm})$.

On the other hand, Fig. 11depicts TGA thermograms of the synthesized polyamides (left curves) and TGA thermogramms of polyamides after thermal treatment (right curves). The weight loss below $120^{\circ} \mathrm{C}$ can be attributed to adsorbed moisture. PTPA, PFPA, PTIPA have similar thermal stability since their $5 \%$ weight loss took place at $232^{\circ}, 195^{\circ}$ and $200^{\circ} \mathrm{C}$ respectively. The sharp drop in PTPA and PFPA thermograms at $228{ }^{\circ} \mathrm{C}$ may be related to carbonyl group decomposition, while the abrupt break at $200{ }^{\circ} \mathrm{C}$ for PTIPA might be related to carboxy-ethenyl group decomposition. PFPA exhibited the lowest thermal stability. The thermal stability changed afterthermal treatment. All polymers presented greater thermal stability when treated at $200^{\circ} \mathrm{C}$. In fact, PTPA, PFPA and PTIPA 5\% weight loss occurred at 244,266 and $254{ }^{\circ} \mathrm{C}$ respectively. Polyamides heating brings about additional crosslinking, suggesting that some vinyl groups remain without reacting during the polymerization process.

Furthermore, PFPA and PTIPA inherent viscosity, using DMSO as solvent, was determined on a Desreux-Bischoff type viscometer at $26^{\circ} \mathrm{C}$. The results, 0.17 and $0.11 \mathrm{dL} \mathrm{g}^{-1}$ respectively, indicated a low degree of polymerization. PTPA low solubility in DMSO precluded inherent viscosity measurement. 

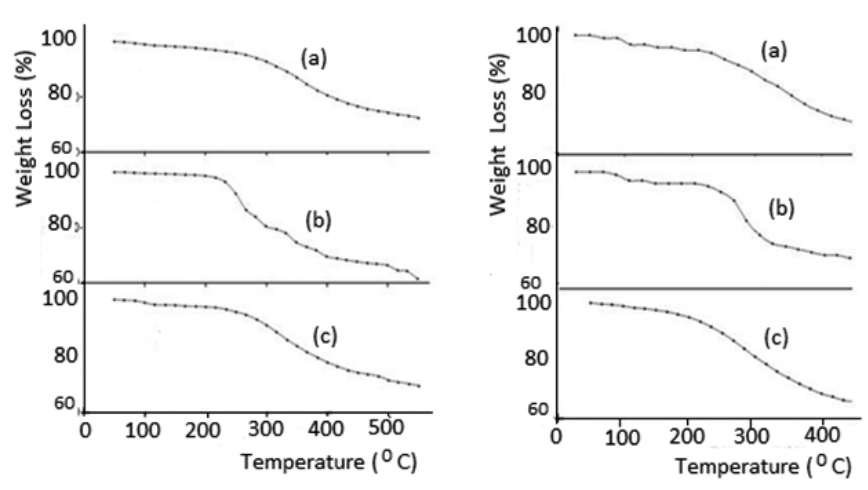

Fig. 11: Polyamides thermograms a) PTPA, b) PFPA, c) PTIPA. Right after thermal treatment

\section{CONCLUSIONS}

New fluorescent crosslinked polyamides containing thiophenyl, furanyl and vinyl groups in their main chain were synthesized by self-condensation from amino-aryl-carboxylic acids. PTPA and PFPA possess high fluorescence emission, however the radiation process decreased after thermal treatment. PTIPA exhibited no fluorescence.

The formation of amide bond, crosslinking, conjugationare are the main factors influencing fluorescence emission.

Polyamides presented fair thermal stability, however increasing their crosslinking degree by heat-treatment a thermal stability rise is attained.

Finally, the synthesized polyamides exhibited potential for heat sensitive devices application since the fluorescence can be activated or quenched according to a heating process.

\section{ACKNOWLEDGEMENTS}

Financial support from Fondecyt No 1120055, 1080119 andis kindly acknowledged.

\section{REFERENCES}

1.- P. E. Cassidy, In: Thermally Stable Polymers: Syntheses and Properties: Marcel Dekker: New York (1980).

2.- J. Zimmerman, In: Polyamides, Encyclopedia of Polymer Science and Engineering, Ed.Wiley: New York, Vol 11, pp 315-321 (1990).

3.- R. A. Gaudiana, R. A Minns, H. G. Rogers, R. Sinta, L. D. Taylor, P. Kalyanaraman, J. Polym. Sci. Part A Polym. Chem. 25,1249, (1987).

4.- M. Steuer, M. Horth, M. Ballauff, J. Polym. Sci. Part A Polym. Chem. 31,1609, (1993).

5.- M. Balasubramanian, M. J. Nanjan, M. Santappa, J. Appl. Polym. Sci. 27, 1423, (1982).

6.- P. W. Morgan, S. L. Kwolek, Macromolecules 8, 104, (1975)

7.- C. D. Diakoumakos, J. A. Mikroyannidis, J. Appl. Polym. Sci. 64, 921, (1997).

8.- O. P. Kwon, J. H. Im, J. H. Kim, S. H. Lee, Macromolecules 33, 9310, (2000).

9.- S. Jeong, G. Kwak, A. Takagi, M. Fujiki, L. S. Park, Eur. Polym. J. 44, $1149,(2008)$.

10.- N. Singletary, R. B. Bates, N. Jacobsen, A. K. Lee, G. A. Lin, A. Somogyi, M. J. Streeter, H. K. Hall, Macromolecules 42, 2336, (2009).

11.- C. O. Sánchez, F. R. Díaz, N. Gatica, C. Bustos, K. Espiñeira, Polym. Bull. 67, 29, (2011).

12.- C. A. Krontiras, J. A. Mikroyannidis, M. N. Pisania, High Perform Polym. 9, 189, (1997).

13.- J. A. Mikroyannidis, C. D. Diakoumakos, Polymer 34, 2227, (1993).

14.- J. A. Mikroyannidis, Polymer 35, 839, (1994).

15.- I. K. Spiliopoulos, J. A. Mikroyannidis, J. Polym. Sci. Part A Polym. Chem. 34, 2799, (1996).

16.- J. A. Mikroyannidis, J. Appl. Polym. Sci. 46, 1001, (1992).

17.- J. A. Mikroyannidis, J. Appl. Polym. Sci. 49, 1749, (1993).

18.- N. Yoshimoto, S. Morino, M. Nakagawa, K. Ichimura Optics Lett. 27, 182, (2002).
19.- G. Hadziioannou, P. F. Van Hutten In: Semiconducting Polymers Chemistry Physics and Engineering, Ed.Wiley: Weinheim -VCH, pp. 661 (2000).

20.- R. H. Friend, G. J. Denton, J. J. M. Halls, N. T. Harrison, A. B. Holmes, A. Kohler, A. Lux, S. C. Moratti, K. Pichler, N. Tessler, Synth. Met. 84, 463, (1997).

21.- W. A. Gazotti, A. F. Nogueira, M. N. Girotto, L. Micaroni, M. Martini, S. Das Neves, M. A. De Paoli, In: Optical devices based on conductive polymers. Handbook of Advanced Electronic and Photonic Materials and Devices, Ed.; Academic Press: New York Vol 10, pp. 53-98 (2001).

22.- R. Kiebooms, R. Menon, K. Lee In: Synthesis, electrical and optical properties of conjugated polymers. Handbook of Advanced Electronic and Photonic Materials and Devices pp 1-102 (2001).

23.- H. Cai, X. H. He, D. Y. Zheng, J. Qiu, J. Polym. Sci. Part A Polym. Chem. 34,1245, (1996).

24.- R. Cagnoli, A. Mucci, F. Parenti, L. Schenetti, M. Borsari, A. Lodi, Polymer 47, 775, (2006).

25.- A. Lodi, M. Caselli, B. Zanfrognini, R. Cagnoli, A. Mucci, F. Parenti, L. Schenetti, G. Ponterini Thin Solid Films 516, 8731 (2008).

26.- R. D. McCullough, P. C. Ewbank In: The Handbook of Conducting Polymers, 2nd ed., Ed.; Marcell Deker: New York, pag 225 (1998).

27.- I. Bugar, M. Zitnan, D. Velic, G. Cik, D. Chorvat, Synth. Met. 157, 834, (2007).

28.- S. J. Toal, W. C. Trogler, J. Mater. Chem. 28, 2871, (2007).

29.- K. Saxena, P. Kumar, P. K. Jain, J Luminescence 130, 2260, (2010).

30.- Y. Xu, L. Zheng, X. Huang, Y. Cheng, C. Zhu, Polymer 51, 994, (2010).

31.- X. Guo, Z. Li, C. Yue, G. Li, Y. Gao, Y. Zhu, Polyhedron 29, 84 (2010).

32.- B. Ranjan, A. J. Chattopadhya, Colloid Interface Sci. 316, 962 (2007).

33.- N. Yamazaki, M. Matsumoto, F. Higashi, J. Polym. Sci. Polym. Chem. Ed. 13, 1373, (1975).

34.- J. R. Dyer, In: Applications of Absorption Spectroscopy of Organic Compounds, Ed.: Prentice -Hall, Inc, Chap. 30 (1975).

35.- S. J. Sung, K. Y. Cho, H. Hah, J. Lee, H. K. Shim, J. K. Park, Polymer 47, 2314, (2006).

36.- S. Pine S, J. B. Hendrickson, D. J. Cram, G. S. Hammond, Quimica Orgánica, 4 ed. Mc Graw Hill (1993).

37.- R. B. Woodward, R. Hoffmann, J. Am. Chem. Soc. 87, 395, (1965). 